\title{
Effects of disodium fumarate on in vitro rumen microbial growth, methane production and fermentation of diets differing in their forage:concentrate ratio
}

\author{
R. García-Martínez, M. J. Ranilla, M. L. Tejido and M. D. Carro* \\ Departamento de Producción Animal I, Universidad de León, 24071 León, Spain \\ (Received 23 September 2004 - Revised 17 January 2005 - Accepted 3 February 2005)
}

\begin{abstract}
The effects of disodium fumarate on microbial growth, $\mathrm{CH}_{4}$ production and fermentation of three diets differing in their forage content $(800,500$ and $200 \mathrm{~g} / \mathrm{kg}$ DM) by rumen micro-organisms in vitro were studied using batch cultures. Rumen contents were collected from four Merino sheep. Disodium fumarate was added to the incubation bottles to achieve final concentrations of 0,4 and 8 mM-fumarate, and ${ }^{15} \mathrm{~N}$ was used as a microbial marker. Gas production was measured at regular intervals from 0 to $120 \mathrm{~h}$ of incubation. Fumarate did not affect $(P>0.05)$ any of the measured gas production parameters. In $17 \mathrm{~h}$ incubations, the final $\mathrm{pH}$ and the production of acetate and propionate were increased linearly $(P<0 \cdot 001)$ by the addition of fumarate. Fumarate tended to increase $(P=0.076)$ the organic matter disappearance of the diets and to decrease $(P=0.079)$ the amount of $\mathrm{NH}_{3}-\mathrm{N}$ in the cultures. Adding fumarate to batch cultures tended $(P=0.099)$ to decrease $\mathrm{CH}_{4}$ production, the mean values of the decrease being $5.4 \%$, $2.9 \%$ and $3.8 \%$ for the high-, medium- and low-forage diet, respectively. Fumarate tended to increase $(P=0.082)$ rumen microbial growth for the high-forage diet, but no differences $(P>0.05)$ were observed for the other two diets. These results indicate that the effects of fumarate on rumen fermentation depend on the nature of the incubated substrate, the high-forage diet showing the greatest response.
\end{abstract}

Fumarate: Rumen microbial growth: Methane: Batch cultures

Methane is one of the major end products of anaerobic fermentation of feeds in the rumen. Reducing $\mathrm{CH}_{4}$ production is an important goal of ruminant nutritionists as it represents a significant loss of energy for the host animal and contributes to global warming (Moss et al. 2000). Many attempts have been made to depress rumen methanogenesis through the use of feed additives as ionophores, halogen compounds, unsaturated fatty acids and organic acids. However, some of these substances simultaneously produce adverse effects on rumen fermentation, such as a depression of fibre digestion or a reduction of protozoal growth (Demeyer \& Fievez, 2000). Conversely, some organic acids (fumarate and malate) have been shown to produce a decrease in $\mathrm{CH}_{4}$ production accompanied by an increase in both the production of volatile fatty acids (VFA) and diet degradation (Isobe \& Shibata, 1993; Carro et al. 1999; López et al. 1999b; Carro \& Ranilla, $2003 a, b)$.

Reported effects of fumarate on $\mathrm{CH}_{4}$ production by rumen micro-organisms are variable. In in vivo trials, Bayaru et al. (2001) reported that fumaric acid supplementation $(20 \mathrm{~g} / \mathrm{kg}$ diet DM) produced a $23 \%$ decrease in $\mathrm{CH}_{4}$ production in steers fed sorghum silage as the only feed, whereas Newbold et al. (2002) only found a $12 \%$ decrease in $\mathrm{CH}_{4}$ when sheep fed grass hay were supplemented with $80 \mathrm{~g}$ fumaric acid/ $\mathrm{kg}$ hay DM. In semicontinuous fermenters, López et al. (1999b) observed a $17 \%$ decrease in $\mathrm{CH}_{4}$ with a mixed diet and $7.35 \mathrm{~mm}$-fumarate. In experiments with batch cultures, the differences between studies are more pronounced. Although small reductions (1.4-7.4\%) have been observed with concentrate feeds (Carro \& Ranilla, 2003a) and a mixed diet (López et al. 1999b) for concentrations of fumarate from 4 to $10 \mathrm{~mm}$, greater effects (ranging from $8 \%$ to $17 \%$ ) have been reported by other authors (Asanuma et al. 1999; Iwamoto et al. 1999; López et al. 1999a) for mixed diets and concentrations of fumarate from 8 to $30 \mathrm{~mm}$.

From these results, it seems that the effect of fumarate on $\mathrm{CH}_{4}$ production by rumen micro-organisms may depend largely on the nature of the fermented substrate and the level of fumarate, but the different experimental conditions in the earlier cited studies (in vivo, fermenters, batch cultures) could also have contributed to the observed differences. The aim of the present study was therefore to evaluate the effects of two doses of fumarate on the $\mathrm{CH}_{4}$ production and in vitro fermentation of three diets differing in their forage:concentrate ratio in batch cultures of mixed rumen micro-organisms.

In addition, several studies have reported a positive effect of fumarate on the growth of different rumen micro-organisms. Nisbet and Martin (1993) reported that $10 \mathrm{mM}$-fumarate stimulated the growth of Selenomonas ruminantium in pure cultures, and Asanuma et al. (1999) showed that $30 \mathrm{mm-fumarate}$ increased the growth of Fibrobacter succinogenes, Selenomonas ruminantium, Veillonella parvula, Selenomonas lactilytica and Wolinella succinogenes in pure cultures. In addition, López et al. (1999b) found a significant increase in the number of cellulolytic bacteria 
when $7.35 \mathrm{~mm}$-fumarate was added to semi-continuous fermenters. To our knowledge, however, no studies have been conducted to investigate the effects of fumarate on the growth of mixed rumen micro-organisms. We therefore decided to measure the in vitro rumen microbial growth in the present experiment using ${ }^{15} \mathrm{~N}$ as a microbial marker.

\section{Materials and methods}

\section{Diets, animals and experimental procedure}

Three diets containing $800 \mathrm{~g}$ (high-forage), $500 \mathrm{~g}$ (medium-forage) and $200 \mathrm{~g}$ (low-forage) forage $/ \mathrm{kg}$ diet DM were formulated. Forage was composed of alfalfa hay and maize silage (500 and $500 \mathrm{~g} / \mathrm{kg}$ $\mathrm{DM}$, respectively), and concentrate was based on barley, maize and soyabean meal $(500,350$ and $150 \mathrm{~g} / \mathrm{kg}$ DM, respectively). The chemical composition of the experimental diets is shown in Table 1. Samples of each diet were ground through a $1 \mathrm{~mm}$ screen and fermented in vitro with buffered rumen fluid.

Rumen fluid was obtained from four rumen-cannulated Merino sheep fed alfalfa hay ad libitum and $400 \mathrm{~g}$ concentrate per d administered in two equal portions at 09.00 and 18.00 hours. Concentrate was based on barley, maize and soyabean meal (390, 400 and $210 \mathrm{~g} / \mathrm{kg}$, respectively). The chemical composition of alfalfa hay and concentrate is given in Table 1.

The rumen contents of each sheep were obtained immediately before the morning feeding, mixed and strained through four layers of cheesecloth into an Erlenmeyer flask with an $\mathrm{O}_{2}$-free headspace. Feed particles were allowed to settle to the bottom ( $5 \mathrm{~min}$ ), and finally the fluid was strained through two layers of nylon cloth $(40 \mu \mathrm{m}$ pore size). Particle-free fluid was mixed with the buffer solution of Goering \& Van Soest (1970) in a proportion $1: 4(\mathrm{v} / \mathrm{v})$ at $39^{\circ} \mathrm{C}$ under continuous flushing with $\mathrm{CO}_{2}$. A dose of ${ }^{15} \mathrm{~N}$ (95\% enriched $\mathrm{SO}_{4}\left({ }^{15} \mathrm{NH}_{4}\right)_{2}$; Sigma Chemical, Madrid, Spain) was added to the medium in a proportion of $2.698 \mathrm{mg}{ }^{15} \mathrm{~N}$ per litre medium to label the ammonia-N pool. Samples $(500 \mathrm{mg})$ of each diet were accurately weighed into $120 \mathrm{ml}$ serum bottles (Laboratorios Ovejero, SA, León, Spain). Fumarate (disodium salt; Sigma Chemical) was added to achieve final fumarate concentrations of 0,4 and $8 \mathrm{~mm}$. Fumarate was dissolved in distilled water, and the corresponding solution $(1 \mathrm{ml})$ was added to each bottle immediately before incubation. Control bottles received $1 \mathrm{ml}$ distilled water. Bottles were prewarmed $\left(39^{\circ} \mathrm{C}\right)$ prior to the addition of $50 \mathrm{ml}$ buffered rumen contents into each one under $\mathrm{CO}_{2}$ flushing. Bottles were sealed with rubber stoppers and aluminium caps, and incubated at $39^{\circ} \mathrm{C}$.

\section{Fermentation kinetics from gas production curves}

Gas production was measured at 3, 6, 9, 12, 16, 21, 26, 31, 36, 48, 60, 72,96 and $120 \mathrm{~h}$ using a pressure transducer and a calibrated syringe. After $120 \mathrm{~h}$ of incubation, the fermentation was stopped by swirling the bottles in ice, the bottles were opened, and their content was transferred to previously weighed filter crucibles. The residue of incubation was washed with $50 \mathrm{ml}$ hot distilled water and dried at $50^{\circ} \mathrm{C}$ for $48 \mathrm{~h}$; the apparent disappearance of substrate was then calculated. The residue was then analysed for ash to calculate the organic matter (OM) apparent disappearance. Two blanks for each fumarate concentration were included to correct the gas production values for gas release from endogenous substrates and added fumarate. The experiment was repeated on 4 different days so that each treatment was conducted in quadruplicate.

\section{Fermentation parameters and microbial growth}

Forty-five bottles with substrate (five bottles for each diet and fumarate concentration) and six bottles without substrate (two bottles per each fumarate concentration; blanks) were incubated. Bottles were withdrawn $17 \mathrm{~h}$ after inoculation (corresponding to a passage rate from the rumen of $0 \cdot 06 / \mathrm{h}$ ), and total gas production was measured in two bottles per diet and treatment as described earlier. A gas sample (about $15 \mathrm{ml}$ ) was removed from each bottle and stored in a Haemoguard Vacutainer (Terumo Europe $\mathrm{NV}$, Leuven, Belgium) before analysis for $\mathrm{CH}_{4}$ concentration. Bottles were uncapped, the $\mathrm{pH}$ was measured immediately with a $\mathrm{pH}$ meter, and the fermentation was stopped by swirling the bottles in ice. One mililitre of the content was added to $1 \mathrm{ml}$ deproteinising solution (metaphosphoric acid $(100 \mathrm{~g} / \mathrm{l})$ and crotonic acid $(0.6 \mathrm{~g} / \mathrm{l}))$ for VFA determination, $2 \mathrm{ml}$ were added to $2 \mathrm{ml}$ $0.5 \mathrm{M}-\mathrm{HCl}$ for $\mathrm{NH}_{3}-\mathrm{N}$ analysis, and $2 \mathrm{ml}$ were stored at $-20^{\circ} \mathrm{C}$ for lactate determination. Finally, the contents of the bottles were transferred to previously weighed filter crucibles. The residue of incubation was washed with $50 \mathrm{ml}$ hot distilled water, dried at $50^{\circ} \mathrm{C}$ for $48 \mathrm{~h}$ and analysed for ash to calculate the apparent $\mathrm{OM}$ disappearance.

The rest of the bottles were used to obtain samples of total digesta and to isolate microbial pellets in order to determine microbial protein synthesis. The contents of the bottles corresponding to each diet and treatment were mixed and homogenised in a blender at low speed for $1 \mathrm{~min}$. One portion (about $60 \mathrm{~g}$ ) was stored at $-20^{\circ} \mathrm{C}$ and freeze-dried to determine DM content; this residue, representative of total digesta, was analysed for non$\mathrm{NH}_{3}-\mathrm{N}$ (NAN), and the ${ }^{15} \mathrm{~N}$ enrichment in the NAN fraction was determined. The rest of the pooled sample was frozen until

Table 1. Chemical composition ( $\mathrm{g} / \mathrm{kg} \mathrm{DM})$ of ingredients of sheep diet and diets incubated in vitro

\begin{tabular}{|c|c|c|c|c|c|}
\hline & Organic matter & Crude protein ${ }^{*}$ & Neutral-detergent fibre & Acid-detergent fibre & ${ }^{15} \mathrm{~N}$ enrichment (\%) \\
\hline \multicolumn{6}{|c|}{ Sheep diet ingredients } \\
\hline Alfalfa hay & 912 & 158 & 472 & 301 & ND \\
\hline Concentrate & 916 & 198 & 151 & $46 \cdot 8$ & ND \\
\hline \multicolumn{6}{|l|}{ Incubated diets } \\
\hline High-forage & 947 & 135 & 387 & 236 & 0.3751 \\
\hline Medium-forage & 956 & 145 & 297 & 164 & 0.3714 \\
\hline Low-forage & 966 & 156 & 208 & $91 \cdot 3$ & $0 \cdot 3711$ \\
\hline
\end{tabular}

ND, not determined

${ }^{*} \mathrm{~N} \times 6 \cdot 25$.

For details of diets of procedures, see p. 72 . 
the isolation of microbial pellets by differential centrifugation following the procedure described by Carro \& Miller (1999). Homogenising and freezing were used as methods to detach solid-associated micro-organisms (Carro \& Miller, 2002), and the isolated microbial pellets were used as a reference to estimate microbial protein synthesis. Microbial pellets were freeze-dried and analysed for $\mathrm{N}$ content and ${ }^{15} \mathrm{~N}$ enrichment. The experiment was repeated on 4 different days.

\section{Analytical procedures}

$\mathrm{DM}$, ash and $\mathrm{N}$ were determined according to the Association of Official Analytical Chemists (1999). Neutral-detergent fibre and acid-detergent fibre analyses were carried out according to Van Soest et al. (1991) and Goering \& Van Soest (1970), respectively. Ammonia-N concentration was analysed by a modified colorimetric method, and VFA concentrations by GC as previously described (Carro et al. 1999). Methane was analysed with a gas chromatograph (Shimadzu GC 14B; Shimadzu Corporation, Kyoto, Japan) equipped with a flame ionisation detector and a column packed with Carboxen 1000 (Supelco, Madrid, Spain). He was used as carrier gas, and peaks were identified by comparison with a standard of known composition. Total lactate was determined in centrifuged samples following the method described by Taylor (1996).

Lyophilised samples of digesta (about $1 \mathrm{~g}$ ) were dampened with distilled water adjusted with $1 \mathrm{M}-\mathrm{NaOH}$ to $\mathrm{pH}>10$ and dried at $90^{\circ} \mathrm{C}$ for $16 \mathrm{~h}$ to remove $\mathrm{NH}_{3}-\mathrm{N}$. The resulting residue was analysed for NAN and for ${ }^{15} \mathrm{~N}$ enrichment. The preparation of samples (digesta and microbial pellets) for ${ }^{15} \mathrm{~N}$ analysis followed the procedure described by Carro \& Miller (1999), and the analysis was performed by isotope ratio MS as described by Barrie \& Workman (1984). Diets were also analysed for their natural ${ }^{15} \mathrm{~N}$ content, and this value was used for background correction before adding ${ }^{15} \mathrm{~N}$.

\section{Calculations}

Gas production values were corrected for gas released from endogenous substrates and added fumarate for each inoculum and fumarate concentration. Corrected values were fitted with time to the exponential model:

$$
\text { gas }=A\left(1-\mathrm{e}^{(-c(t-\text { lag time }))}\right),
$$

where $A$ is the asymptotic gas production, $c$ is the fractional rate of gas production, lag time is the initial delay in the onset of gas production and $t$ is the gas-reading time. The parameters $A, c$ and lag time were estimated by an iterative least squares procedure using the PROC NLIN of the Statistical Analysis Systems Institute (version 6, 1989; SAS Institute Inc., Cary, NY, USA). The effective degradability of dietary OM was estimated assuming a rumen particulate outflow of $0 \cdot 06 / \mathrm{h}$, according to the equation proposed by France et al. (2000). The average gas production rate $(\mathrm{ml}$ gas $/ \mathrm{h})$ was defined as the average gas production rate between the start of the incubation and the time at which the cumulative gas production was half of its asymptotic value, and was calculated as:

$$
\text { rate }=A \mathrm{c} /[2(\ln 2+c \text { lag time })]
$$

The amounts of VFA produced were obtained by subtracting the amount initially present in the incubation medium from that determined at the end of the incubation period. The volume of gas produced $(\mathrm{ml})$ was corrected for temperature $(273 \mathrm{~K})$ and pressure $\left(1.013 \times 10^{5} \mathrm{~Pa}\right)$ conditions to calculate the $\mu \mathrm{mol}$ of gas produced. The amount of $\mathrm{CH}_{4}(\mu \mathrm{mol})$ was calculated by multiplying the gas produced $(\mu \mathrm{mol})$ by the concentration of $\mathrm{CH}_{4}$ in the analysed sample.

The proportion of digesta NAN of microbial origin was estimated for each diet and fumarate concentration by dividing the ${ }^{15} \mathrm{~N}$ enrichment (atom \% excess) of the NAN portion of digesta by the enrichment of the corresponding microbial pellet. Daily microbial $\mathrm{N}$ production $(\mathrm{mg} / \mathrm{d})$ was estimated in each bottle by multiplying total NAN by the proportion attributed to the microbes (Ranilla et al. 2001).

\section{Statistical analyses}

Data were analysed as a factorial design with three concentrations of fumarate (0, 4 and $8 \mathrm{~mm})$, three diets (high-, medium- and lowforage), four incubation runs and the interaction fumarate $\times$ diet included in the model. Orthogonal polynomial contrasts were performed to determine linear and quadratic effects of fumarate treatment. All the statistical analyses were performed using the general linear models procedures of the Statistical Analysis Systems Institute (version 6, 1989; SAS Institute Inc.). Within each diet, there were four values for each treatment for gas production variables, diet $\mathrm{OM}$ disappearance after $17 \mathrm{~h}$ of incubation and microbial protein synthesis, and eight values for the rest of the measured variables

\section{Results}

Table 2 shows the effects of fumarate treatment and diet on gas production parameters and $\mathrm{OM}$ effective degradability. There were no effects $(P>0 \cdot 05)$ of fumarate on any of the measured parameters, but all of them were significantly affected by the incubated diet. The high-forage diet showed the lowest $(P<0.05)$ values of asymptotic gas production $(A)$ and fractional rate of gas production $(c)$, and the greatest $(P<0.05)$ values of $l a g$ time.

The effects of fumarate and diet on final $\mathrm{pH}$, diet $\mathrm{OM}$ apparent disappearance and the production of $\mathrm{NH}_{3}-\mathrm{N}$, lactate and microbial $\mathrm{N}$ are shown in Table 3 . The addition of fumarate increased linearly $(P<0.001)$ the final $\mathrm{pH}$, and tended to increase the diet $\mathrm{OM}$ apparent disappearance $(P=0.076)$ and decrease the final amount of $\mathrm{NH}_{3}-\mathrm{N}$ in the cultures $(P=0 \cdot 079)$. There were, however, no effects $(P>0.05)$ of the addition of fumarate on the amounts of lactate and microbial $\mathrm{N}$, although fumarate tended $(P=0.082)$ to increase microbial growth with the high-forage diet. No significant $(P>0.05)$ interactions between fumarate and diet were detected for any of the measured variables.

As shown in Table 4, the addition of fumarate linearly increased $(P<0.001)$ the production of acetate and propionate, and tended $(P=0.099)$ to decrease $\mathrm{CH}_{4}$ production linearly. As a consequence of these changes, the ratio $\mathrm{CH}_{4}$ :VFA decreased linearly $(P<0.001)$ as the concentration of fumarate increased. Adding fumarate to the cultures did not affect $(P>0.05)$ the production of butyrate and other VFA. No significant interactions $(P>0.05)$ between fumarate and diet were detected. The production of both propionate and butyrate was augmented $(P<0.001)$ as the proportion of concentrate in the diet increased, 
Table 2. Influence of disodium fumarate on gas production parameters ( $A, c$ and lag time), average gas production (AGPR) and organic matter effective degradability (OMED) of diets with a high (HF), medium (MF) and low (LF) forage content incubated in batch cultures of mixed rumen micro-organisms

(Mean values with their standard errors for four fermentations) ${ }^{\star}$

\begin{tabular}{|c|c|c|c|c|c|c|c|c|c|}
\hline \multirow{2}{*}{ Item } & \multirow{2}{*}{ Diet } & & & & \multirow{2}{*}{ SED } & \multicolumn{4}{|c|}{ Statistical significance of the effects $(P<) \dagger$} \\
\hline & & \multicolumn{3}{|c|}{ Fumarate (mM) } & & \multicolumn{2}{|c|}{ Fumarate $\ddagger$} & Diet & Fumarate $\times$ diet \\
\hline \multirow[t]{2}{*}{$A(\mathrm{ml})$} & HF & 148 & 151 & 151 & $3 \cdot 0$ & NS & NS & 0.001 & NS \\
\hline & MF & 162 & 166 & 167 & & & & & \\
\hline \multirow{2}{*}{$c\left(\mathrm{~h}^{-1}\right)$} & MF & 0.0656 & 0.0679 & 0.0678 & & & & & \\
\hline & LF & 0.0680 & 0.0688 & 0.0693 & & & & & \\
\hline \multirow[t]{3}{*}{ Lag time (h) } & HF & $1 \cdot 75$ & $1 \cdot 71$ & 1.69 & 0.254 & NS & NS & 0.001 & NS \\
\hline & MF & $1 \cdot 20$ & 0.94 & 1.02 & & & & & \\
\hline & LF & 0.551 & 0.531 & 0.567 & & & & & \\
\hline AGPR (ml/h) & HF & $5 \cdot 94$ & $6 \cdot 12$ & $6 \cdot 11$ & 0.381 & NS & NS & 0.001 & NS \\
\hline OMED (\%) & LF & $46 \cdot 5$ & $46 \cdot 3$ & $46 \cdot 2$ & & & & & \\
\hline
\end{tabular}

${ }^{*} 50 \mathrm{ml}$ diluted buffered rumen contents were incubated for $120 \mathrm{~h}$ with $500 \mathrm{mg}$ ground diet; for details of diets and procedures, see p. 72 and Table 1.

† NS; $P>0.10$ ( $P$ values between 0.05 and 0.10 are considered as trends and reported).

$\ddagger$ Linear, linear effect of fumarate dose; quadratic, quadratic effect of fumarate dose.

but there were no differences $(P>0.05)$ between diets in the production of acetate and other VFA.

\section{Discussion}

An increase in gas production due to fumarate supplementation has been consistently observed in batch cultures of mixed rumen micro-organisms (Callaway \& Martin, 1996; López et al. 1999b; Carro \& Ranilla, 2003a). In the present experiment, when gas production values were corrected only for gas release from endogenous substrates, fumarate increased $(P<0 \cdot 05)$ gas production for the three diets at all sampling times, with the exception of $2 \mathrm{~h}$ after incubation (results not shown). As $\mathrm{CO}_{2}$ is an end product of fumarate fermentation to propionate via the succinate-propionate pathway (Demeyer \& Henderickx, 1967), the observed increase in gas production could stem from fumarate

Table 3. Influence of disodium fumarate on final $\mathrm{pH}$, organic matter apparent disappearance (OMAD), production of $\mathrm{NH}_{3} \mathrm{~N}$, lactate and microbial $\mathrm{N}$ and efficiency of microbial growth (EMG) during the in vitro fermentation of diets with a high (HF), medium (MF) and low (LF) forage content by mixed rumen micro-organisms (Mean values for eight fermentations for $\mathrm{pH}, \mathrm{NH}_{3} \mathrm{~N}$ and lactate, and for four fermentations for the rest of parameters) ${ }^{*}$

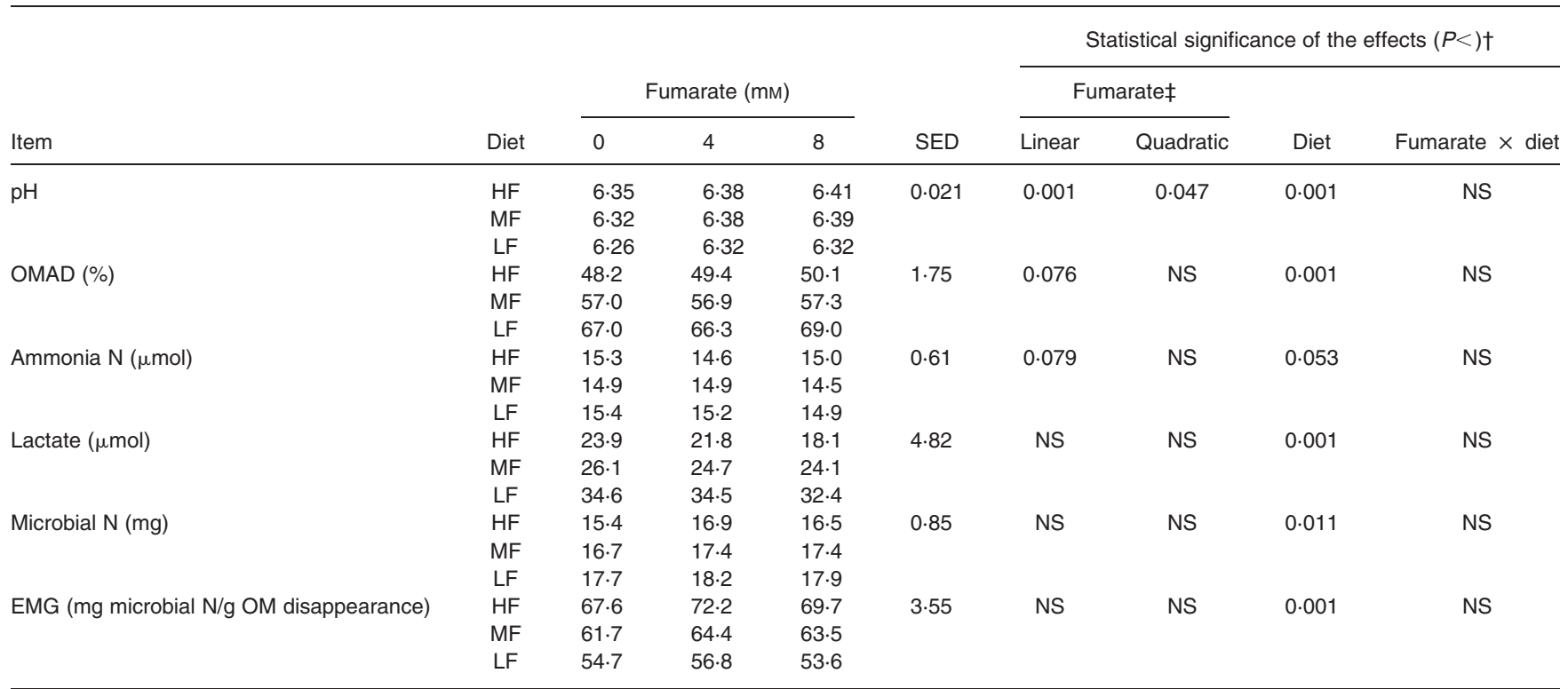

*50 ml diluted buffered rumen contents were incubated for $17 \mathrm{~h}$ with $500 \mathrm{mg}$ ground diet; for details of diets and procedures, see p. 72 and Table 1 . 
Table 4. Influence of disodium fumarate on $\mathrm{CH}_{4}$ and volatile fatty acid (VFA) production during the in vitro fermentation of diets with a high (HF), medium (MF) and low (LF) forage content by mixed rumen micro-organisms

(Mean values for eight fermentations)*

\begin{tabular}{|c|c|c|c|c|c|c|c|c|c|}
\hline \multirow[b]{3}{*}{ Item } & \multirow[b]{3}{*}{ Diet } & & & & \multirow[b]{3}{*}{ SED } & \multicolumn{4}{|c|}{ Statistical significance of the effects $(P<) \dagger$} \\
\hline & & \multicolumn{3}{|c|}{ Fumarate (mм) } & & \multicolumn{2}{|c|}{ Fumarateł } & \multirow[b]{2}{*}{ Diet } & \multirow[b]{2}{*}{ Fumarate $\times$ die } \\
\hline & & 0 & 4 & 8 & & Linear & Quadratic & & \\
\hline \multirow[t]{3}{*}{ Methane $(\mu \mathrm{mol})$} & $\mathrm{HF}$ & 701 & 661 & 665 & $25 \cdot 2$ & NS & NS & 0.001 & NS \\
\hline & MF & 754 & 737 & 728 & & & & & \\
\hline & LF & 812 & 780 & 783 & & & & & \\
\hline \multirow[t]{3}{*}{ Acetate } & $\mathrm{HF}$ & 1902 & 1994 & 2095 & $44 \cdot 2$ & 0.001 & NS & NS & NS \\
\hline & MF & 1917 & 1999 & 2065 & & & & & \\
\hline & LF & 1925 & 2009 & 2153 & & & & & \\
\hline \multirow[t]{3}{*}{ Propionate } & $\mathrm{HF}$ & 699 & 842 & 954 & 20.9 & 0.001 & NS & 0.004 & NS \\
\hline & MF & 744 & 874 & 955 & & & & & \\
\hline & LF & 759 & 853 & 1007 & & & & & \\
\hline \multirow[t]{2}{*}{ Butyrate } & $\mathrm{HF}$ & 456 & 494 & 495 & $21 \cdot 9$ & NS & NS & 0.001 & NS \\
\hline & MF & 546 & 568 & 539 & & & & & \\
\hline & MF & 127 & 137 & 126 & & & & & \\
\hline & LF & 119 & 125 & 128 & & & & & \\
\hline \multirow[t]{3}{*}{ Total VFA } & $\mathrm{HF}$ & 3182 & 3463 & 3682 & $64 \cdot 5$ & 0.001 & NS & 0.001 & NS \\
\hline & MF & 3334 & 3578 & 3684 & & & & & \\
\hline & LF & 3378 & 3572 & 3879 & & & & & \\
\hline \multirow[t]{3}{*}{ Acetate:propionate ( $\mu \mathrm{mol}: \mu \mathrm{mol})$} & $\mathrm{HF}$ & $2 \cdot 75$ & $2 \cdot 38$ & $2 \cdot 21$ & 0.077 & 0.001 & NS & NS & NS \\
\hline & MF & $2 \cdot 64$ & $2 \cdot 31$ & $2 \cdot 18$ & & & & & \\
\hline & LF & 2.58 & $2 \cdot 41$ & $2 \cdot 15$ & & & & & \\
\hline \multirow[t]{3}{*}{ Methane:VFA ( $\mu \mathrm{mol}: \mu \mathrm{mol})$} & $\mathrm{HF}$ & 0.221 & 0.191 & 0.181 & 0.0076 & 0.001 & NS & 0.004 & NS \\
\hline & MF & 0.228 & 0.207 & 0.200 & & & & & \\
\hline & LF & 0.242 & 0.219 & $0 \cdot 202$ & & & & & \\
\hline
\end{tabular}

${ }^{*} 50 \mathrm{ml}$ diluted buffered rumen contents were incubated for $17 \mathrm{~h}$ with $500 \mathrm{mg}$ ground diet; for details of diets and procedures, see p. 72 and Table 1.

†NS: $P>0.10$ ( $P$ values between 0.05 and 0.10 are considered as trends and reported).

$\ddagger$ Linear, linear effect of fumarate dose; quadratic, quadratic effect of fumarate dose.

$\S$ Calculated as the sum of isobutyrate, isovalerate, valerate and caproate.

fermentation itself. In the present experiment, we included blanks containing 4 and $8 \mathrm{~mm}$-fumarate (in addition to the incubation medium) in order also to correct the values for the amount of gas produced by the fermentation of fumarate itself. The lack of effects $(P>0.05)$ of fumarate on any of the measured gas production parameters (Table 2) would indicate that the increase in gas production observed in the fumarate-treated cultures stemmed from the fermentation of fumarate.

In agreement with the results previously reported by other authors (Callaway \& Martin, 1996; Asanuma et al. 1999; López et al. 1999b; Carro \& Ranilla, 2003a) for diets of variable composition incubated in batch cultures of mixed rumen micro-organisms, the addition of fumarate increased $(P<0.001)$ the final $\mathrm{pH}$ linearly in the present experiment. This effect has also been found in vivo; thus, Isobe \& Shibata (1993) observed a greater $\mathrm{pH}$ in the rumen of goats fed two diets (containing $20 \%$ or $50 \%$ crashed maize) when fumaric acid was added to the feed $(50 \mathrm{~g} / \mathrm{kg}$ diet $)$, the authors attributing this effect to a stimulation of saliva secretion caused by added fumarate. In contrast, Bayaru et al. (2001) did not find any differences caused by the addition of fumaric acid $(20 \mathrm{~g} / \mathrm{kg}$ diet $\mathrm{DM})$ in rumen $\mathrm{pH}$ in steers fed sorghum silage as the only feed. The incubation medium used in batch cultures contains a buffer solution to counteract the drop in $\mathrm{pH}$ caused by the production of VFA and lactate. Callaway \& Martin (1996) suggested that fumarate might act to buffer rumen contents by a dual mechanism of increased lactate utilisation by Selenomonas ruminantium and $\mathrm{CO}_{2}$ production. In the present experiment, the addition of fumarate did not affect $(P>0 \cdot 05)$ lactate concentrations, although it increased total gas production with all the diets.

$\mathrm{H}$ is used to reduce fumarate in the rumen and, as a consequence, there is a decrease in the availability of $\mathrm{H}_{2}$ for methanogenesis, which could decrease $\mathrm{CH}_{4}$ production (Callaway \& Martin, 1996). A reduction in $\mathrm{CH}_{4}$ production owing to the addition of fumarate has been found in most of the studies conducted: in steers (Bayaru et al. 2001) and sheep (Newbold et al. 2002), in semi-continuous fermenters (López et al. 1999b) and in batch cultures (Asanuma et al. 1999; Iwamoto et al. 1999; López et al. 1999b; Carro \& Ranilla, 2003a). Asanuma et al. (1999) stated that the addition of fumarate to ruminant feed possibly increased the number of fumarate-utilising bacteria in the rumen. This could help to explain some of the observed differences in the reduction of $\mathrm{CH}_{4}$ production reported in the previously cited studies.

Reductions of $12 \%$ (Newbold et al. 2002) and $23 \%$ (Bayaru et al. 2001) have been observed in sheep and steers, respectively, when animals were fed forage as the only feed, and López et al. (1999b) found a $17 \%$ decrease by adding fumarate to semi-continuous fermenters fed a mixed diet. In these experiments, fumarate was added to the diet for at least $7 \mathrm{~d}$ before measuring $\mathrm{CH}_{4}$ production. In contrast, $\mathrm{CH}_{4}$ production in batch cultures has been measured after short periods of time $(6-24 \mathrm{~h}$ in the 
experiments reported), and smaller reductions in $\mathrm{CH}_{4}$ were found in some of these studies; reductions ranging from $1.4 \%$ to $7.4 \%$ have been reported by López et al. (1999b) with a mixed diet and by Carro \& Ranilla (2003a) with concentrate feeds when batch cultures were supplemented with different doses of fumarate (4-10 mM).

Greater reductions have, however, been observed in other in vitro studies with batch cultures. Asanuma et al. (1999) reported an $11 \%$ decrease with a mixed diet and $30 \mathrm{~mm}$-fumarate, López et al. (1999a) found an $8 \%$ decrease with a forage-based diet $(750 \mathrm{~g} / \mathrm{kg} \mathrm{DM}$ diet) and $8 \mathrm{~mm}$-fumarate, and Iwamoto et al. (1999) reported a decrease of $17 \%$ with $10 \mathrm{~mm}$-fumarate and a diet composed of starch and cellulose (666 and $333 \mathrm{~g} / \mathrm{kg}$, respectively). Noticeably, López et al. (1999b) found a $17 \%$ decrease in $\mathrm{CH}_{4}$ production in semi-continuous fermenters supplemented with 7.35 mM-disodium fumarate, but when the same diet was incubated in batch cultures of mixed rumen micro-organisms for $24 \mathrm{~h}$, the addition of 5 and $10 \mathrm{~mm}$-disodium fumarate decreased the $\mathrm{CH}_{4}$ production by only $5.3 \%$ and $6.4 \%$, respectively. In these experiments, rumen fluid from the same sheep was used to inoculate both systems (fermenters and batch cultures), and the differences in $\mathrm{pH}$ observed between the two systems (mean values of 6.78 and 6.47 for fermenters and batch cultures, respectively) do not seem to justify the marked differences observed in the reduction of $\mathrm{CH}_{4}$ production (Van Kessel \& Russell, 1996).

The $\mathrm{CH}_{4}$ decrease found in the present experiment is fairly consistent with the response reported by other authors in batch cultures. Although the decrease in $\mathrm{CH}_{4}$ was greater for the high-forage diet (5.7\% and $5.1 \%$ for 4 and $8 \mathrm{~mm}$-fumarate, respectively) than for the other two diets (mean values for both fumarate concentrations being $2.9 \%$ and $3.8 \%$ for the medium- and low-forage diets, respectively), the present values indicate that fumarate would be impractical as a means of effectively reducing $\mathrm{CH}_{4}$ emissions in vivo, as has been previously stated (López et al. 1999b). Further research is needed to clarify whether the observed discrepancies in the effects of fumarate on $\mathrm{CH}_{4}$ production in the rumen are due to the use of different diets and/or experimental conditions (in vivo, rumen fermenters or batch cultures).

Fumarate can be converted into propionate and acetate following different pathways (Demeyer \& Henderickx, 1967). In the present experiment, the addition of fumarate linearly increased $(P<0.001)$ the production of both acids, but the magnitude of the observed response differed between diets. Calculated recoveries of fumarate as acetate plus propionate were lower than or similar to $100 \%$ for the medium-forage diet (mean values of $88 \%$ and $104 \%$ for 4 and 8-mm fumarate, respectively) and for the low-forage diet when $4 \mathrm{~mm}$-fumarate was added $(87 \%)$. In contrast, recoveries higher than $100 \%$ were observed for the high-forage diet $(115 \%$ and $110 \%$ for 4 and 8 -mm fumarate, respectively) and for the low-forage diet supplemented with 8 -mm fumarate $(117 \%)$. These results would indicate that the in vitro fermentation of these diets was stimulated by the addition of fumarate, but the increase in acetate and propionate production observed for the other incubations could stem from fumarate fermentation itself. When incubations with 4 and $8 \mathrm{~mm}$-fumarate were conducted in absence of incubated substrates (blanks; results not shown), fumarate recovery as acetate plus propionate was $93 \%$ and $86 \%$ for the 4 and $8 \mathrm{~mm}$ concentrations, respectively. The fact that these recoveries were lower than $100 \%$ could be explained by an incomplete fermentation of fumarate after $17 \mathrm{~h}$ of incubation and/or by the accumulation of other final products (i.e. succinate). However, an incomplete fermentation of fumarate seems improbable, as Asanuma et al. (1999) reported that mixed rumen micro-organisms fermenting hay powder and concentrate consumed $100 \%$ of the added fumarate $(30 \mathrm{~mm})$ after $9 \mathrm{~h}$ of incubation, and no succinate accumulation was detected after $12 \mathrm{~h}$ of incubation.

Although several studies (Nisbet \& Martin, 1993; Asanuma et al. 1999) have reported a positive effect of fumarate on the growth of some rumen micro-organisms in pure cultures, no information on the effects of fumarate on the growth of mixed rumen micro-organisms was available; we therefore used ${ }^{15} \mathrm{~N}$ as microbial marker to measure microbial $\mathrm{N}$ production in the present study. A trend $(P=0.082)$ towards a greater microbial growth produced by fumarate was detected for the high-forage diet, but no significant effects were observed for the other two diets. These results are in agreement with the greater response to fumarate supplementation observed for the high-forage diet in the production of VFA.

As expected, microbial growth increased as the proportion of concentrate in the diet augmented $(15.4,16.7$ and $17.7 \mathrm{mg}$ microbial $\mathrm{N}$ for the high-, medium- and low-forage diet, respectively). Microbial $\mathrm{N}$ production values were in the range of those previously found by our group in batch cultures of mixed rumen micro-organisms fermenting starch and/or cellulose (Tejido et al. 2001). In contrast, the values of efficiency of microbial growth were considerably greater than others reported in the literature from in vitro experiments (Illg \& Stern, 1994). The efficiency of microbial growth is affected by a great number of factors, but the values obtained can also be strongly influenced by the techniques and microbial markers used to measure it (Dewhurst et al. 2000). In addition, microbial growth has several stages (lag, growth, stationary and decline), and in batch cultures these stages relative to incubation time will vary between substrates (Blümmel et al. 2003). In this experiment, microbial N production was measured after $17 \mathrm{~h}$ of incubation, which could be considered as a stage of great microbial growth, and this can partly explain the great efficiency of microbial growth observed. In any case, fumarate treatment did not affect the efficiency of microbial growth with any diet.

The results of the present study suggest that fumarate had a mild beneficial effect on the in vitro rumen fermentation of diets of different composition by increasing final $\mathrm{pH}$ and the production of acetate and propionate, and by decreasing $\mathrm{CH}_{4}$ production. The greater response found for the high-forage diet in comparison with the other two diets would indicate that fumarate utilisation in vitro could depend on the nature of the fermented substrate. In any case, long-term studies with diets of different composition are required to assess the dietary conditions that influence the effectiveness of fumarate.

\section{Acknowledgements}

The authors wish to acknowledge the financial support received from the Spanish Ministerio de Ciencia y Tecnología (Project AGL2001-0130) and JCYL (Project LE62/03). M. J. R. gratefully acknowledges receipt of a research contract from the Spanish MCYT (Programa Ramón y Cajal). Analyses of ${ }^{15} \mathrm{~N}$ isotope ratios were performed at the SIDI of the Universidad Autónoma de Madrid (Spain). 


\section{References}

Asanuma N, Iwamoto M \& Hino T (1999) Effect of the addition of fumarate on methane production by ruminal microorganisms in vitro. J Dairy Sci 82, 780-787.

Association of Official Analytical Chemists (1999) Official Methods of Analysis, 16th ed. 5th revision Gaithersburg, MD: AOAC International.

Barrie S \& Workman CT (1984) An automated analytical system for nutritional investigations using N-15 tracers. Spectr Int J 3, 439-447.

Bayaru E, Kanda S, Kamada T, Itabashi H, Andoh S, Nishida T, Ishida M, Itoh T, Nagara K \& Isobe Y (2001) Effect of fumaric acid on methane production, rumen fermentation and digestibility of cattle fed roughage alone. Anim Sci J 72, 139-146.

Blümmel M, Karsi A \& Russell JR (2003) Influence of diet on growth yields of rumen micro-organisms in vitro and in vivo: influence on growth yield of variable carbon fluxed to fermentation products. $\mathrm{Br} J$ Nutr 90, 625-634.

Callaway TR \& Martin SA (1996) Effects of organic acid and monensin treatment on in vitro mixed ruminal microorganism fermentation of cracked corn. J Anim Sci 74, 1982-1989.

Carro MD, López S, Valdés C \& Ovejero FJ (1999) Effect of DL-malate on mixed ruminal microorganism fermentation using the rumen simulation technique (RUSITEC). Anim Feed Sci Technol 79, 279-288.

Carro MD \& Miller EL (1999) Effect of supplementing a fibre basal diet with different nitrogen forms on ruminal fermentation and microbial growth in an in vitro semicontinuous culture system (RUSITEC). $\mathrm{Br}$ J Nutr 82, 149-157.

Carro MD \& Miller EL (2002) Comparison of microbial markers $\left({ }^{15} \mathrm{~N}\right.$ and purine bases) and bacterial isolates for the determination of rumen microbial protein synthesis. Anim Sci 75, 315-321.

Carro MD \& Ranilla MJ (2003a) Influence of different concentrations of disodium fumarate on methane production and fermentation of concentrate feeds by rumen micro-organisms in vitro. Br J Nutr 90, 617-623.

Carro MD \& Ranilla MJ (2003b) Effect of the addition of malate on in vitro rumen fermentation of cereal grains. Br J Nutr 89, 279-288.

Demeyer DI \& Fievez V (2000) Ruminants et environnement: la méthanogenèse (Ruminants and environment: methanogenesis). Ann Zootech 49, 95-112.

Demeyer DI \& Henderickx MK (1967) Competitive inhibition of in vitro methane production by mixed rumen bacteria. Arch Int Phys Bioch 75, $157-159$.

Dewhurst RJ, Davies DR \& Merry RJ (2000) Microbial protein supply from the rumen. Anim Feed Sci Technol 85, 1-21.

France J, Dijkstra J, Dhanoa MS, López S \& Bannick A (2000) Estimating the extent of degradation of ruminant feeds from a description of their gas production profiles observed in vitro: a derivation of models and other mathematical considerations. Br J Nutr 83, 143-150.
Goering MK \& Van Soest PJ (1970) Forage Fiber Analysis (Apparatus, Reagents, Procedures and Some Applications). Agricultural Handbook no. 379. Washington DC: Agricultural Research Services, USDA.

Illg DJ \& Stern MD (1994) In vitro and in vivo comparisons of diaminopimelic acid and purines for estimating protein synthesis in the rumen. Anim Feed Sci Technol 48, 49-55.

Isobe Y \& Shibata F (1993) Rumen fermentation in goats administered fumaric acid. Anim Sci Technol 64, 1024-1030.

Iwamoto M, Asanuma N \& Hino T (1999) Effects of nitrate combined with fumarate on methanogenesis, fermentation, and cellulose digestion by rumen microbes in vitro. Anim Sci J 70, 471-478.

López S, Newbold CJ, Bochi-Brum O, Moss AR \& Wallace RJ (1999a) Propionate precursors and other metabolic intermediates as possible alternative electron acceptors to methanogenesis in ruminal in vitro. S Afr J Anim Sci 29, 106-107.

López S, Valdés C, Newbold CJ \& Wallace RJ (1999b) Influence of sodium fumarate addition on rumen fermentation in vitro. $\mathrm{Br} J \mathrm{Nutr}$ 81, 59-64.

Moss AR, Jouany JP \& Newbold J (2000) Methane production by ruminants: its contribution to global warming. Ann Zootech 49, $231-253$.

Newbold CJ \& Ouda JO, López S, Nelson N, Omed H, Wallace RJ \& Moss AR (2002) Propionate precursors as possible alternative electron acceptors to methane in ruminal fermentation. In Greenhouse Gases and Animal Agriculture, Proceedings, pp. 151-154 [J Takahashi and BA Young editors]. Greenhouse Gases and Animal Agriculture, Proceedings. Amsterdam: Elsevier.

Nisbet DJ \& Martin SA (1993) Effects of fumarate, L-malate, and an Aspergillus oryzae fermentation extract on D-lactate utilization by the ruminal bacterium Selenomonas ruminantium. Curr Microbiol 26, $133-136$.

Ranilla MJ, Carro MD, López S, Newbold JC \& Wallace J (2001) Influence of $\mathrm{N}$ source on the fermentation of fibre from barley straw and sugarbeet pulp by ruminal micro-organisms in vitro. Br J Nutr 86, $717-724$.

Taylor KACC (1996) A simple colorimetric assay for muramic acid and lactic acid. Appl Biochem Biotechnol 56, 49-58.

Tejido ML, Carro MD, Ranilla MJ \& López S (2001) In vitro microbial growth as affected by the type of carbohydrate and the source of $\mathrm{N}$. In Proceedings of the Winter Meeting of the British Society of Animal Science, pp. 152. York: British Society of Animal Science.

Van Kessel JAS \& Russell JB (1996) The effect of pH on ruminal methanogenesis. FEMS Microbiol Ecol 20, 205-210.

Van Soest PJ, Robertson JB \& Lewis BA (1991) Methods for dietary fiber, neutral detergent fiber, and nonstarch polysaccharides in relation to animal nutrition. J Dairy Sci 74, 3583-3597. 